Gazi University
Journal of Science
PART C: DESIGN AND TECHNOLOGY
http://dergipark.gov.tr/gujsc

\title{
s-to-z Transformation Tool for Discretization
}

\author{
Fahri VATANSEVER $^{1 *}$ (D) Metin HATUN ${ }^{1}$ (D) \\ ${ }^{I}$ Bursa Uludağ University, Faculty of Engineering, Electrical-Electronics Eng. Dept. 16059 Bursa/Turkey
}

\section{Article Info \\ Research article \\ Received: 01.10.2021 \\ Revision: 05.12.2021 \\ Accepted: 05.12.2021}

\section{Keywords}

s-to-z transform

$s$-to-z transformation

$s$-to-z mapping

$s-z$ transform

discretization

\begin{abstract}
The signals/systems in nature are analog in terms of their sources. These continuous-time signals/systems need to be discretized in order to be used in digital systems (processing, storage etc.). For this purpose, different methods have been developed and continue to be developed. In the work carried out; a software tool with a user-friendly interface has been designed that performs discretization of continuous-time systems with different methods in a fast, accurate and effective manner, presents single or comparative results (parameters, responses, etc.) both numerically and graphically.
\end{abstract}

\section{INTRODUCTION}

Because of the physical systems are naturally analog, the signals related to these systems are represented in continuous-time. By developments of digital systems in parallel with progress of technology, various discrete-time techniques have been developed for analysis and design of continuous-time systems. In order to integrate classical analog systems into digital systems, discrete models or discrete equivalents must be obtained by discretization. Transformation of continuous-time to discrete-time is the fundamental operation in discrete signal processing and discrete circuit design. This process, which is expressed with concepts such as "s - to - z transform", "s - to - z transformation", "s - z transform", " s - to - z mapping" provides a transition from s-domain to z-domain.

There are many methods in the literature for $\mathrm{s}-$ to $-\mathrm{z}$ transformation: backward or forward difference, bilinear (Tustin) transform, impulse/step/ramp invariance/invariant methods, magnitude/phase invariance methods, matched $\mathrm{z}$ transform etc. [1-10]. The main purpose of all these methods developed using different approaches is to obtain the discrete-time equivalent that best describes the transfer function of the continuous-time system. However, as the order of the systems increases, it becomes more difficult to perform the relevant transformations manually or to use higher order $\mathrm{s}-\mathrm{z}$ transformations.

As a result of the development in the computers, computer-aided technologies (CAx) concepts (such as computer-aided analysis (CAA), computer-aided design (CAD), computer-aided engineering (CAE), computer-aided instruction (CAI), computer-aided learning (CAL), computer-aided manufacturing (CAM), computer-aided software, computer-aided software engineering (CASE), etc.) have currently gained a significant place. Simulators, applications, web pages, etc. are developed in many areas using computer software. There are many studies in the field of system analysis with software in the literature [11-21]. However, there are not many software with a user-friendly interface that is specially designed for discretization and can perform these operations quickly, accurately and effectively with many different methods. For example, the "c2d" discretization command in MATLAB does this in just six different methods and provides numerical results [22]. 
In this study, a software tool has been developed that discretizes the continuous-time transfer functions with different methods. With this developed software, very high order transfer functions in the s-domain are transferred to the $z$-domain easily, effectively and quickly with the selected method or methods (comparative analysis). In addition, the software provides detailed numerical and graphical results of continuous and discrete time transfer functions.

This paper is organized as follows: In Section 2, s - to $-\mathrm{z}$ mapping functions are summarized. In Section 3, designed software tool is explained and sample applications are given. Finally, Section 4 contains conclusions.

\section{2. s-to-z MAPPING FUNCTIONS}

Different $\mathrm{s}-$ to $-\mathrm{z}$ mapping functions are available for obtaining discrete equivalents/models of continuous time functions. From the similarities in discrete expressions of the unilateral Laplace transform and $z$-transform of a continuous-time function $f(t)$ (Table 1),

$$
F(s)=\left.F(z)\right|_{z=e^{s T}} \Rightarrow\left\{\begin{array}{c}
z=e^{s T} \\
s=\frac{1}{T} \operatorname{Ln}(z)
\end{array}\right.
$$

is obtained, where $T$ is the sampling period. Some fundamental mapping functions can be obtained from the Taylor series of $s$ ve $z$ [23] using first terms are given in Table 2 .

$$
\left\{\begin{array}{c}
z=e^{s T}=1+\frac{s T}{1 !}+\frac{(s T)^{2}}{2 !}+\cdots=\sum_{k=0}^{\infty} \frac{(s T)^{k}}{k !} \\
S=\frac{1}{T} \operatorname{Ln}(z)=\frac{2}{T}\left\{\frac{z-1}{z+1}+\frac{1}{3}\left(\frac{z-1}{z+1}\right)^{3}+\cdots\right\}=\frac{2}{T} \sum_{k=1}^{\infty} \frac{1}{2 k-1}\left(\frac{z-1}{z+1}\right)^{2 k-1}
\end{array}\right.
$$

Table 1. Unilateral Laplace and Z-transforms

\begin{tabular}{|l|c|}
\hline \multicolumn{1}{|c|}{ Transform } & Discrete-time expression \\
\hline $\begin{array}{l}\text { Unilateral } \\
\text { Laplace } \\
\text { transform }\end{array}$ & $F(s)=\sum_{n=0}^{\infty} f[n] e^{-s n T}$ \\
\hline $\begin{array}{l}\text { Unilateral } z- \\
\text { transform }\end{array}$ & $F(z)=\sum_{n=0}^{\infty} f[n] z^{-n}$ \\
\hline
\end{tabular}

Table 2. Popular $s-$ to $-z$ mapping methods

\begin{tabular}{|l|c|c|}
\hline \multicolumn{1}{|c|}{ Method/Rule } & $\boldsymbol{s}$ & $\mathbf{z}$ \\
\hline $\begin{array}{l}\text { Forward } \\
\text { difference / }\end{array}$ & $s=\frac{z-1}{T}$ & $z=1+s T$ \\
$\begin{array}{l}\text { Forward } \\
\text { rectangular }\end{array}$ & $s=\frac{z-1}{T z}$ & $z=\frac{1}{1-s T}$ \\
\hline $\begin{array}{l}\text { Backward } \\
\text { difference/ } \\
\text { Backward } \\
\text { rectangular }\end{array}$ & $s=\frac{2}{T} \frac{z-1}{z+1}$ & $z=\frac{1+s T / 2}{1-s T / 2}$ \\
\hline $\begin{array}{l}\text { Bilinear / } \\
\text { Tusapezoidal / }\end{array}$ & \\
\hline
\end{tabular}

The general classification of $s-$ to $-\mathrm{z}$ mapping methods is given in Figure 1 [2]. Matching responses methods are based on matching system responses (impulse, step etc.) (Table 3).

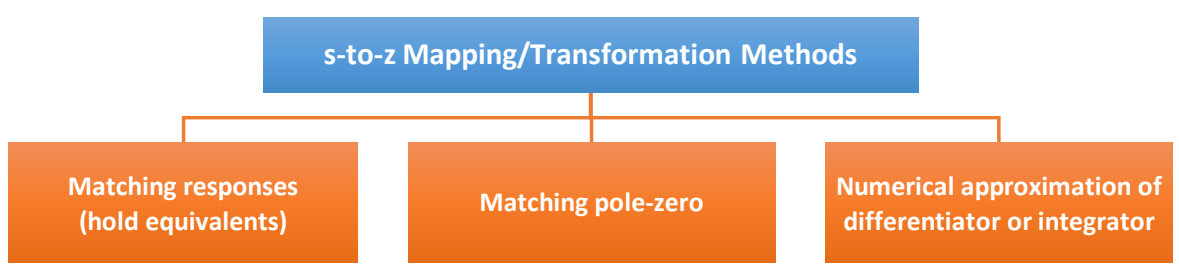

Figure 1. The general classification of s-to-z mapping methods

For example, the impulse-invariant discrete-time system equivalent of the continuous-time system with the transfer function $H(s)$ is obtained as follows:

- Obtain the impulse response of continuous-time system: $h(t)=\mathrm{L}^{-1}\{H(s)\}$

- Derive samples $h(k)$ from $h(t)$ with suitable sampling interval: $h(k)=\left.h(t)\right|_{t=k T}$ 
- Obtain $z$-transform of $h(k): H(z)=\mathrm{z}\{h(k)\}$

This process can be represented by

$$
H(z)=\mathrm{z}\left\{\left.\mathrm{L}^{-1}\{H(s)\}\right|_{t=k T}\right\}
$$

and this operation commonly indicated as

$$
H(z)=Z\{H(s)\}
$$

Table 3. The some methods based on matching step and other responses

\begin{tabular}{|l|c|}
\hline \multicolumn{1}{|c|}{ Method } & Definition $[H(z)]$ \\
\hline Impulse invariance & $z\{H(s)\}$ \\
\hline Step invariance $(\mathrm{ZOH})$ & $z\left\{\frac{1-e^{-s T}}{s} H(s)\right\}=\left(\frac{z-1}{z}\right) z\left\{\frac{H(s)}{s}\right\}$ \\
\hline Ramp invariance (FOH) & $z\left\{\frac{1-e^{-s T}}{s^{2}} H(s)\right\}=\frac{(z-1)^{2}}{T z} z\left\{\frac{H(s)}{s^{2}}\right\}$ \\
\hline
\end{tabular}

\begin{tabular}{|c|c|c|c|}
\hline & Integrator: $\frac{1}{s}$ & Real poles/zeros: $s+a$ & Complex poles/zeros: $(s+a)^{2}+b^{2}$ \\
\hline 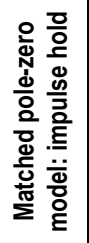 & $\frac{z-1}{T z}$ & $\frac{z-e^{-a T}}{T z}$ & $\frac{z^{2}-2 z e^{-a T} \operatorname{Cos}(b T)-e^{-a T}}{(T z)^{2}}$ \\
\hline 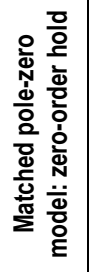 & $\frac{z-1}{T}$ & $\frac{z-e^{-a T}}{T}$ & $\frac{z^{2}-2 z e^{-a T} \operatorname{Cos}(b T)-e^{-2 a T}}{T^{2}}$ \\
\hline 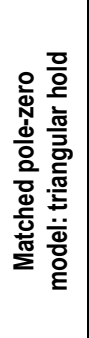 & $\frac{2}{T} \frac{z-1}{z+1}$ & $\frac{a^{2}}{a-\frac{1-e^{-a T}}{T}} \frac{z-e^{-a T}}{\left.z-\frac{\left(a e^{-a T}-\frac{1-e^{-a T}}{T}\right.}{T}\right)}$ & $\begin{array}{c}\frac{\left(a^{2}+b^{2}\right) T}{\alpha} \frac{z^{2}-2 z e^{-a T} \operatorname{Cos}(b T)-e^{-2 a T}}{z^{2}-\frac{\gamma}{\alpha} z+\frac{\beta}{\alpha}} \\
\alpha=e^{-2 a T}+\left(a^{2}+b^{2}\right) T-2 a T-2 e^{-2 a T} \operatorname{Cos}(b T) \\
+2 e^{-a T}\{\operatorname{aCos}(b T)-b \operatorname{Sin}(b T)\} \\
\beta=e^{-2 a T}+2 a T e^{-2 a T}+\left(a^{2}+b^{2}\right) T^{2} e^{-2 a T} \\
-2 e^{-a T} \operatorname{Cos}(b T)-2 T e^{-a T}\{\operatorname{acos}(b T)+b \operatorname{Sin}(b T)\} \\
\gamma=2\left\{\begin{array}{c}e^{-2 a T}+a T e^{-2 a T}+1+\left(a^{2}+b^{2}\right) T^{2} e^{-a T} \cos (b T) \\
-a-2 e^{-a T} \operatorname{Cos}(b T)-2 b T e^{-a T} \operatorname{Sin}(b T)\end{array}\right\}\end{array}$ \\
\hline
\end{tabular}

Table 4. Some matched pole-zero models

Matching pole-zero (pole-zero matching, pole-zero mapping, matched $z$-transform method) is a method based on mapping all poles and zeros of continuous-time system in $s$-plane to $z$-plane locations $\left(z=e^{s T}\right)$ for a sample interval (Table 4) [24]. This procedure is summarized as follow:

- Map all poles and zeros of system according to $z=e^{s T}$.

- If order of the numerator is lower than the denominator, add powers of $(z+1)$ to the numerator until the orders are equal.

- Set equivalent DC or low-frequency gain.

Numerical approximations of differentiator or integrator methods are based on the use of numerical approaches instead of derivatives or integrals in the continuous-time system equation. For example, using the finite differences for the derivative and the rectangular and trapezoidal rules for the integral, the 
results in Table 2 are given in Table 5 and Table 6, respectively. In many transformation methods, the discrete-time transfer function is obtained by using the substitution method: $Z\left\{\left(s^{ \pm 1}\right)^{k}\right\}=\left[Z\left\{s^{ \pm 1}\right\}\right]^{k}$. But, it should be noted that in some substitution methods, the terms may change depending on the degree of derivative and integrator, namely: $Z\left\{\left(s^{ \pm 1}\right)^{k}\right\} \neq\left[Z\left\{s^{ \pm 1}\right\}\right]^{k}$, as seen at Table 7. In Table 8, many methods based on numerical approximation are given [1-5, 10, 25-54].

Table 5. Obtaining the methods in Table 2 with finite difference approximation of derivatives

\begin{tabular}{|c|c|c|c|c|}
\hline & order differential equation & \multicolumn{2}{|c|}{ Laplace transform } & Transfer function (s-domain) \\
\hline \multicolumn{2}{|r|}{$y^{\prime}(t)+y(t)=x(t)$} & \multicolumn{2}{|c|}{$s Y(s)+Y(s)=X(s)$} & $\frac{Y(s)}{X(s)}=\frac{1}{s+1}$ \\
\hline \multirow{3}{*}{ 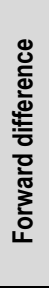 } & \multirow{3}{*}{$y^{\prime}(t)=\left.\frac{d y(t)}{d t}\right|_{t=k T}=\frac{y}{}$} & & Substituting & $\frac{y(k+1)-y(k)}{T}+y(k)=x(k)$ \\
\hline & & & z-transform & $\frac{z Y(z)-Y(z)}{T}+Y(z)=X(z)$ \\
\hline & & & $\begin{array}{l}\text { Transfer } \\
\text { function }\end{array}$ & $\frac{Y(z)}{X(z)}=\frac{1}{\frac{z-1}{T}+1}$ \\
\hline \multirow{3}{*}{ 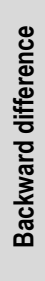 } & \multirow{3}{*}{$y^{\prime}(t)=\left.\frac{d y(t)}{d t}\right|_{t=k T}=$} & & Substituting & $\frac{y(k)-y(k-1)}{T}+y(k)=x(k)$ \\
\hline & & & z-transform & $\frac{Y(z)-z^{-1} Y(z)}{T}+Y(z)=X(z)$ \\
\hline & & & $\begin{array}{l}\text { Transfer } \\
\text { function }\end{array}$ & $\frac{Y(z)}{X(z)}=\frac{1}{\frac{1-z^{-1}}{T}+1}$ \\
\hline
\end{tabular}

Table 6. Obtaining the methods in Table 2 with rectangular and trapezoidal rules for integration

\begin{tabular}{|c|c|c|c|c|}
\hline \multicolumn{2}{|r|}{ 1st order differential equation } & \multicolumn{2}{|c|}{ Integration } & Transfer function (s-domain) \\
\hline \multicolumn{2}{|r|}{$y^{\prime}(t)+y(t)=x(t)$} & $y(t)=y(0)-\int_{0}$ & $\int^{t} y(\tau) d \tau+\int_{0}^{t} x(\tau) d \tau$ & $\frac{Y(s)}{X(s)}=\frac{1}{s+1}$ \\
\hline \multirow{3}{*}{ 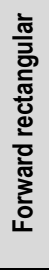 } & \multirow{3}{*}{$\int_{(k-1) T}^{k T} y(t) d t \cong y(k-1) T$} & Substituting & \multicolumn{2}{|c|}{$y(k)=y(k-1)-y(k-1) T+x(k-1) T$} \\
\hline & & z-transform & \multicolumn{2}{|c|}{$Y(z)=z^{-1} Y(z)-z^{-1} Y(z) T+z^{-1} X(z) T$} \\
\hline & & $\begin{array}{l}\text { Transfer } \\
\text { function }\end{array}$ & & $\frac{Y(z)}{X(z)}=\frac{1}{\frac{z-1}{T}+1}$ \\
\hline \multirow{3}{*}{ 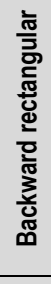 } & \multirow{3}{*}{$\int_{(k-1) T}^{k T} y(t) d t \cong y(k) T$} & Substituting & \multicolumn{2}{|c|}{$y(k)=y(k-1)-y(k) T+x(k) T$} \\
\hline & & z-transform & \multicolumn{2}{|c|}{$Y(z)=z^{-1} Y(z)-Y(z) T+X(z) T$} \\
\hline & & $\begin{array}{l}\text { Transfer } \\
\text { function }\end{array}$ & & $\frac{Y(z)}{X(z)}=\frac{1}{\frac{1-z^{-1}}{T}+1}$ \\
\hline \multirow{3}{*}{ 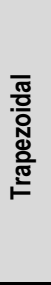 } & \multirow{3}{*}{$\int_{(k-1) T}^{k T} y(t) d t \cong \frac{y(k)+y(k-1)}{2} T$} & Substituting & \multicolumn{2}{|c|}{$y(k)=y(k-1)-\frac{y(k)+y(k-1)}{2} T+\frac{x(k)+x(k-1)}{2} T$} \\
\hline & & z-transform & \multicolumn{2}{|c|}{$Y(z)=z^{-1} Y(z)-Y(z)\left(1+z^{-1}\right) \frac{T}{2}+X(z)\left(1+z^{-1}\right) \frac{T}{2}$} \\
\hline & & $\begin{array}{l}\text { Transfer } \\
\text { function }\end{array}$ & & $\frac{Y(z)}{X(z)}=\frac{1}{\frac{2(z-1)}{T(z+1)}+1}$ \\
\hline
\end{tabular}


Table 7. Common substitution methods [25]

\begin{tabular}{|c|c|c|c|c|}
\hline Method & $s^{-1}$ & $s^{-2}$ & $s^{-3}$ & $s^{-4}$ \\
\hline Backward & $T z$ & $T^{2} z^{2}$ & $T^{3} z^{3}$ & $T^{4} z^{4}$ \\
\hline rectangular & $\overline{z-1}$ & $\overline{(z-1)^{2}}$ & $\overline{(z-1)^{3}}$ & $\overline{(z-1)^{4}}$ \\
\hline \multirow{2}{*}{$\begin{array}{l}\text { Bilinear (Tustin) } \\
\text { transform }\end{array}$} & $T z+1$ & $T^{2}(z+1)^{2}$ & $T^{3}(z+1)^{3}$ & $T^{4}(z+1)^{4}$ \\
\hline & $\overline{2} \overline{z-1}$ & $\overline{4} \overline{(z-1)^{2}}$ & $\overline{8} \overline{(z-1)^{3}}$ & $\overline{16} \overline{(z-1)^{4}}$ \\
\hline \multirow{2}{*}{ z-transform } & $z$ & $T z$ & $T^{2}\left(z^{2}+z\right)$ & $T^{3}\left(z^{3}+4 z^{2}+z\right)$ \\
\hline & $\overline{z-1}$ & $\overline{(z-1)^{2}}$ & $\overline{2} \overline{(z-1)^{3}}$ & $\overline{6} \frac{(z-1)^{4}}{(z)}$ \\
\hline \multirow{2}{*}{ Halijak } & $T z$ & $T^{2} Z$ & $T^{3}\left(z^{2}+z\right)$ & $T^{4}\left(z^{3}+2 z^{2}+z\right)$ \\
\hline & $\overline{z-1}$ & $\overline{(z-1)^{2}}$ & $2 \frac{(z-1)^{3}}{(z)}$ & $(z-1)^{4}$ \\
\hline \multirow{2}{*}{ Boxer-Thaler } & $T z+1$ & $T^{2}\left(z^{2}+10 z+1\right)$ & $T^{3}\left(z^{2}+z\right)$ & $T^{4}\left(z^{3}+4 z^{2}+z\right)-T^{4}$ \\
\hline & $\overline{2} \overline{z-1}$ & $\overline{12}(z-1)^{2}$ & $2 \overline{(z-1)^{3}}$ & $\overline{6} \quad(z-1)^{4}$ \\
\hline \multirow{2}{*}{ Madwed } & $T z+1$ & $T^{2}\left(z^{2}+4 z+1\right)$ & $T^{3}\left(z^{3}+11 z^{2}+11 z+1\right)$ & $T^{4}\left(z^{4}+26 z^{3}+66 z^{2}+26 z+1\right)$ \\
\hline & $\overline{2} \overline{z-1}$ & $\overline { 6 } \longdiv { ( z - 1 ) ^ { 2 } }$ & $(z-1)^{3}$ & $(z-1)^{4}$ \\
\hline
\end{tabular}

Table 8. The some methods based on numerical approximation

\begin{tabular}{|c|c|c|}
\hline Method & Differentiator (s) & Integrator $(1 / s)$ \\
\hline $\begin{array}{l}\text { Forward rectangular integration (Euler } \\
\text { approximation of first order) }\end{array}$ & $\frac{z-1}{T}$ & $\frac{T z^{-1}}{1-z^{-1}}$ \\
\hline $\begin{array}{l}\text { Backward rectangular integration (Euler } \\
\text { approximation of second order) }\end{array}$ & $\frac{z-1}{T z}$ & $\frac{T}{1-z^{-1}}$ \\
\hline $\begin{array}{l}\text { Trapezoidal integration } \\
\text { (Bilinear / Tustin method) }\end{array}$ & $\frac{2}{T} \frac{z-1}{z+1}$ & $\frac{T}{2} \frac{1+z^{-1}}{1-z^{-1}}$ \\
\hline $\begin{array}{l}\text { Trapezoidal integration with prewarping } \\
\text { (Bilinear / Tustin method with prewarping) }\end{array}$ & $\frac{\omega_{0}}{\tan \left(\frac{\omega_{0} T}{2}\right)} \frac{z-1}{z+1}$ & $\frac{\tan \left(\frac{\omega_{0} T}{2}\right)}{\omega_{0}} \frac{1+z^{-1}}{1-z^{-1}}$ \\
\hline Compensated trapezoidal integration & $\frac{2}{T} \frac{n(z-1)}{(n+2) z+(n-2)}$ & $\frac{T}{2} \frac{1+z^{-1}}{1-z^{-1}}+\frac{T}{n}$ \\
\hline Upward parabolic integration & $\frac{3}{T} \frac{z-1}{2 z+1}$ & $\frac{T}{3} \frac{2+z^{-1}}{1-z^{-1}}$ \\
\hline Downward parabolic integration & $\frac{3}{T} \frac{z-1}{z+2}$ & $\frac{T}{3} \frac{1+2 z^{-1}}{1-z^{-1}}$ \\
\hline $\begin{array}{l}\text { Al-Alaoui minimum phase integrator-1 (for } \\
a=3 / 4 \text { ). (Stabilized version of Al-Alaoui } \\
\text { nonminimum phase integrator-1) }\end{array}$ & $\frac{8}{7 T} \frac{z-1}{z+(1 / 7)}$ & $\frac{7 T}{8} \frac{1+(1 / 7) z^{-1}}{1-z^{-1}}$ \\
\hline $\begin{array}{l}\text { Al-Alaoui minimum phase integrator-2 (for } \\
a=3 / 4 \text { ) (combined backward } \\
\text { rectangular and trapezoidal integration } \\
\text { rules) } \\
H_{B T}(z)=a H_{B}(z)+(1-a) H_{T}(z)\end{array}$ & $\frac{8}{7 T} \frac{z-1}{z+(1 / 7)}$ & $\frac{7 T}{8} \frac{1+(1 / 7) z^{-1}}{1-z^{-1}}$ \\
\hline $\begin{array}{l}\text { Al-Alaoui minimum phase integrator-3 } \\
\text { (Stabilized version of Al-Alaoui } \\
\text { nonminimum phase integrator-3) }\end{array}$ & $\begin{array}{c}\frac{6\left(z^{2}-1\right)}{\operatorname{Tr}_{1}(3-a)\left(z+r_{2}\right)}, \quad(0 \leq a \leq 1) \\
r_{2}=\frac{3+a-2 \sqrt{3 a}}{3-a}\end{array}$ & $\begin{array}{c}\frac{T r_{1}(3-a)\left(z+r_{2}\right)}{6\left(z^{2}-1\right)},(0 \leq a \leq 1) \\
r_{2}=\frac{3+a-2 \sqrt{3 a}}{3-a}\end{array}$ \\
\hline $\begin{array}{l}\text { Al-Alaoui nonminimum phase integrator-1 } \\
\text { for } a=3 / 4 \text {. (combined forward } \\
\text { rectangular and trapezoidal integration } \\
\text { rules) } \\
H_{F T}(z)=a H_{F}(z)+(1-a) H_{T}(z)\end{array}$ & $\frac{8}{T} \frac{z-1}{z+7}$ & $\frac{T}{8} \frac{1+7 z^{-1}}{1-z^{-1}}$ \\
\hline $\begin{array}{l}\text { Al-Alaoui nonminimum phase integrator-2 } \\
\text { (combined Simpson } 1 / 3 \text { and trapezoidal } \\
\text { integration rules) } \\
H_{S T}(z)=a H_{S}(z)+(1-a) H_{T}(z)\end{array}$ & $\begin{array}{c}\frac{6\left(z^{2}-1\right)}{T(3-a)\left[\left(z+r_{1}\right)\left(z+r_{2}\right)\right]} \\
r_{1}=\frac{3+a+2 \sqrt{3 a}}{3-a}, r_{2}=\frac{3+a-2 \sqrt{3 a}}{3-a} \\
r_{1}=1 / r_{2}, \quad(0 \leq a \leq 1)\end{array}$ & $\begin{array}{l}\frac{T(3-a)\left[\left(z+r_{1}\right)\left(z+r_{2}\right)\right]}{6\left(z^{2}-1\right)} \\
r_{1}=\frac{3+a+2 \sqrt{3 a}}{3-a}, r_{2}=\frac{3+a-2 \sqrt{3 a}}{3-a} \\
r_{1}=1 / r_{2}, \quad(0 \leq a \leq 1)\end{array}$ \\
\hline $\begin{array}{l}\text { Le Bihan nonminimum phase integrator } \\
\text { for } \chi=0,793 \text {. } \\
H_{F T}(z)=\chi H_{F}(z)+(1-\chi) H_{T}(z)\end{array}$ & $\frac{2}{T} \frac{z-1}{(1-\chi) z+(1+\chi)}$ & $\frac{T}{2} \frac{(1-\chi)+(1+\chi) z^{-1}}{1-z^{-1}}$ \\
\hline $\begin{array}{l}\text { Le Bihan minimum phase integrator (for } \\
\chi=0,793 \text { ). (Stabilized version of Le } \\
\text { Bihan nonminimum phase integrator) }\end{array}$ & $\frac{2}{T} \frac{z-1}{(1+\chi) z+(1-\chi)}$ & $\frac{T}{2} \frac{(1+\chi)+(1-\chi) z^{-1}}{1-z^{-1}}$ \\
\hline Tick integration rule & $\frac{2,7902}{T} \frac{z^{2}-1}{z^{2}+3,5804 z+1}$ & $\frac{T}{2,7902} \frac{1+3,5804 z^{-1}+z^{-2}}{1-z^{-2}}$ \\
\hline
\end{tabular}




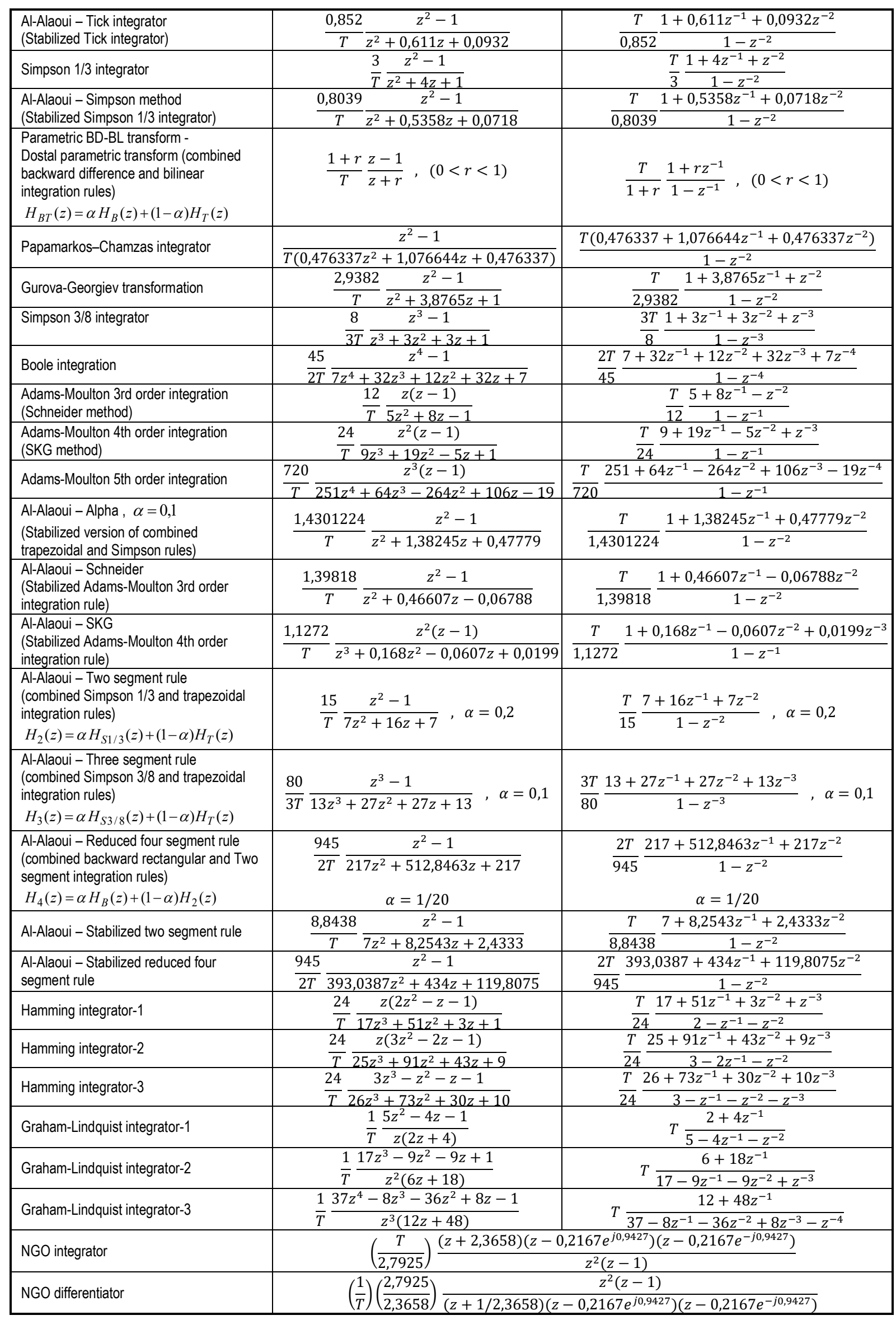




\section{DESIGNED TOOL and APPLICATIONS}

In this study, an application/simulator was designed using MATLAB App Designer [22] for $\mathrm{s}-$ to $-\mathrm{z}$ transformation/mapping, which is one of the most important application areas of signal processing. With this application, discretization operations can be performed with numerous different methods easily, quickly and effectively. In addition, the effectiveness of the methods can be clearly observed by performing single or comparative analyzes, because the application produces many numerical and graphical results (transfer functions of systems, zeros, poles, responses, etc.). Besides, it supports a better understanding of $s-$ to $-\mathrm{z}$ transformation/mapping methods with its use in the field of education.

The first application is a fifth order filter with real poles, two real zeros and a dc gain of $1 / 1152$ (sampling time is $0.01 \mathrm{~s}$ ) [55] which is given with following transfer function:

$$
H(s)=\frac{s^{2}+2 s+0.75}{s^{5}+27.5 s^{4}+261.5 s^{3}+1039 s^{3}+1668 s+864}
$$

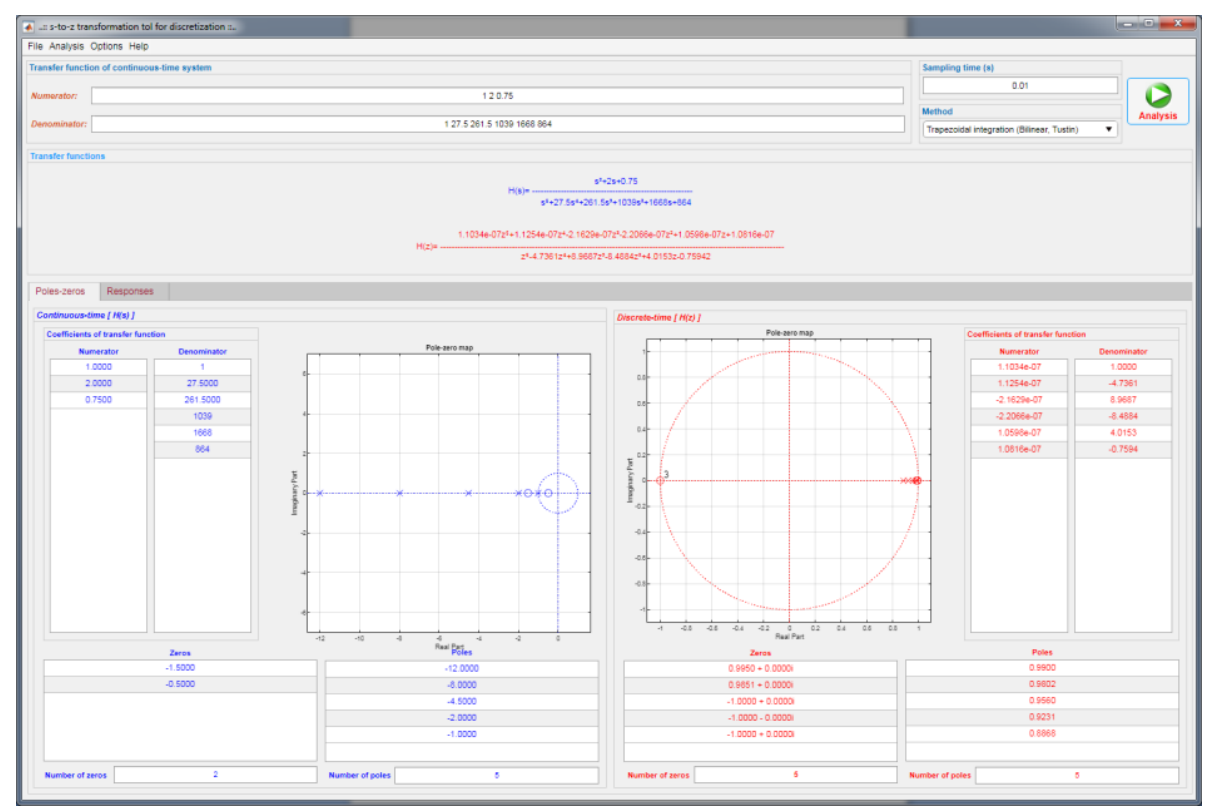

(a)

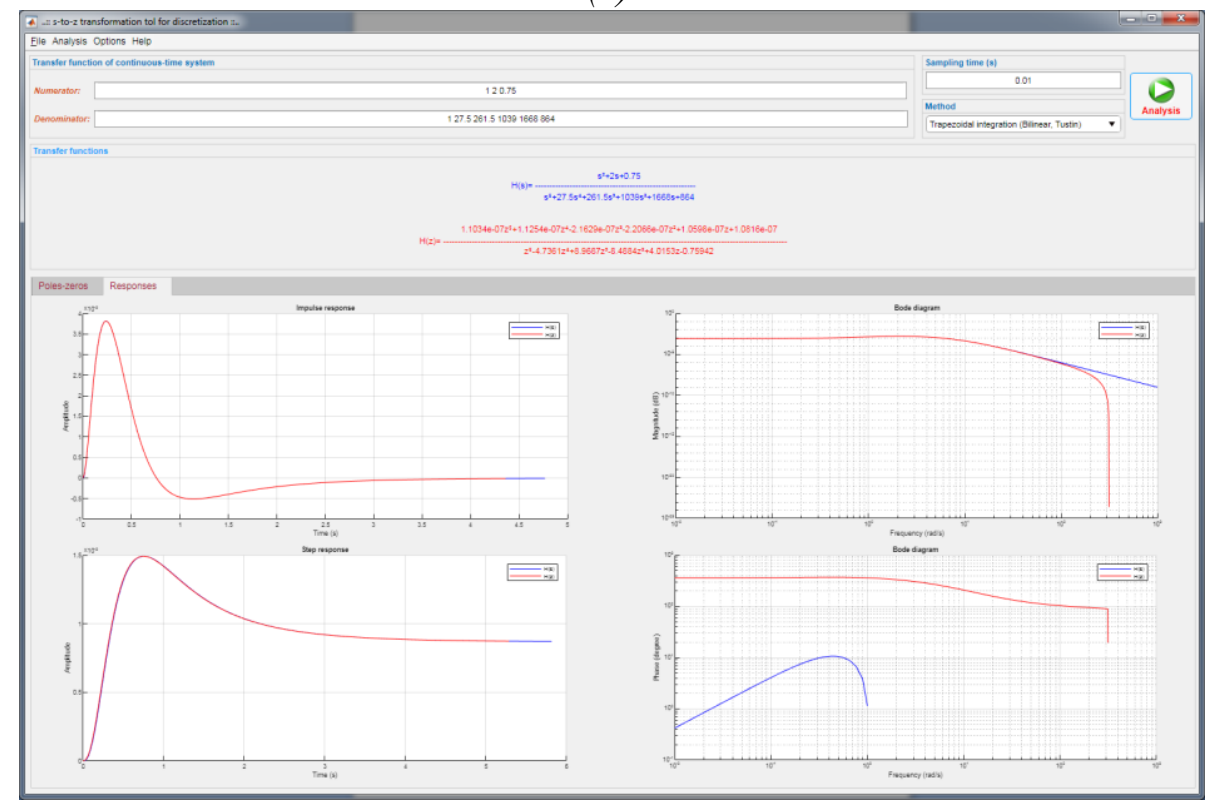

(b)

Figure 2. The screenshots for first application 
The results of discretization using bilinear (Tustin) method are given in Figure 2. As seen in Figure 2, in the designed application, the numerator and denominator coefficients of the transfer function of the continuous-time system are entered, the sampling time is determined, and the method to be used is selected. As a result of the analysis performed, the transfer functions of both continuous-time model and its discrete-time equivalent are shown and the pole-zero maps of these transfer functions are plotted, and also the pole-zero numbers are given (Figure 2a). In addition, the impulse and step responses and Bode diagrams of both continuous time model and its discrete-time equivalent are plotted (Figure 2b).

The second application is a sixth order Butterworth filter (sampling time is $0.01 \mathrm{~s}$ ) [3] which is given with following transfer function:

$$
H(s)=\frac{1}{\left(s^{2}+2 \operatorname{Cos}(5 \pi / 12) s+1\right)\left(s^{2}+2 \operatorname{Cos}(\pi / 12) s+1\right)\left(s^{2}+\sqrt{2} s+1\right)}
$$

The results of comparative discretization using Schneider transform, trapezoidal integration (bilinear, Tustin) method and Al-Alaoui-Schneider transform are given in Figure 3. In the comparison screen, the transfer function of the continuous time system is discretized with 3 different methods selected; the numerator and denominator coefficients of the discrete time transfer functions and their zeros and poles are listed. In addition, the unit impulse and step responses of discrete-time systems obtained by both continuous-time and comparative methods are plotted comparatively. Thus, the discretization efficiency of each method on the relevant system can be clearly observed.

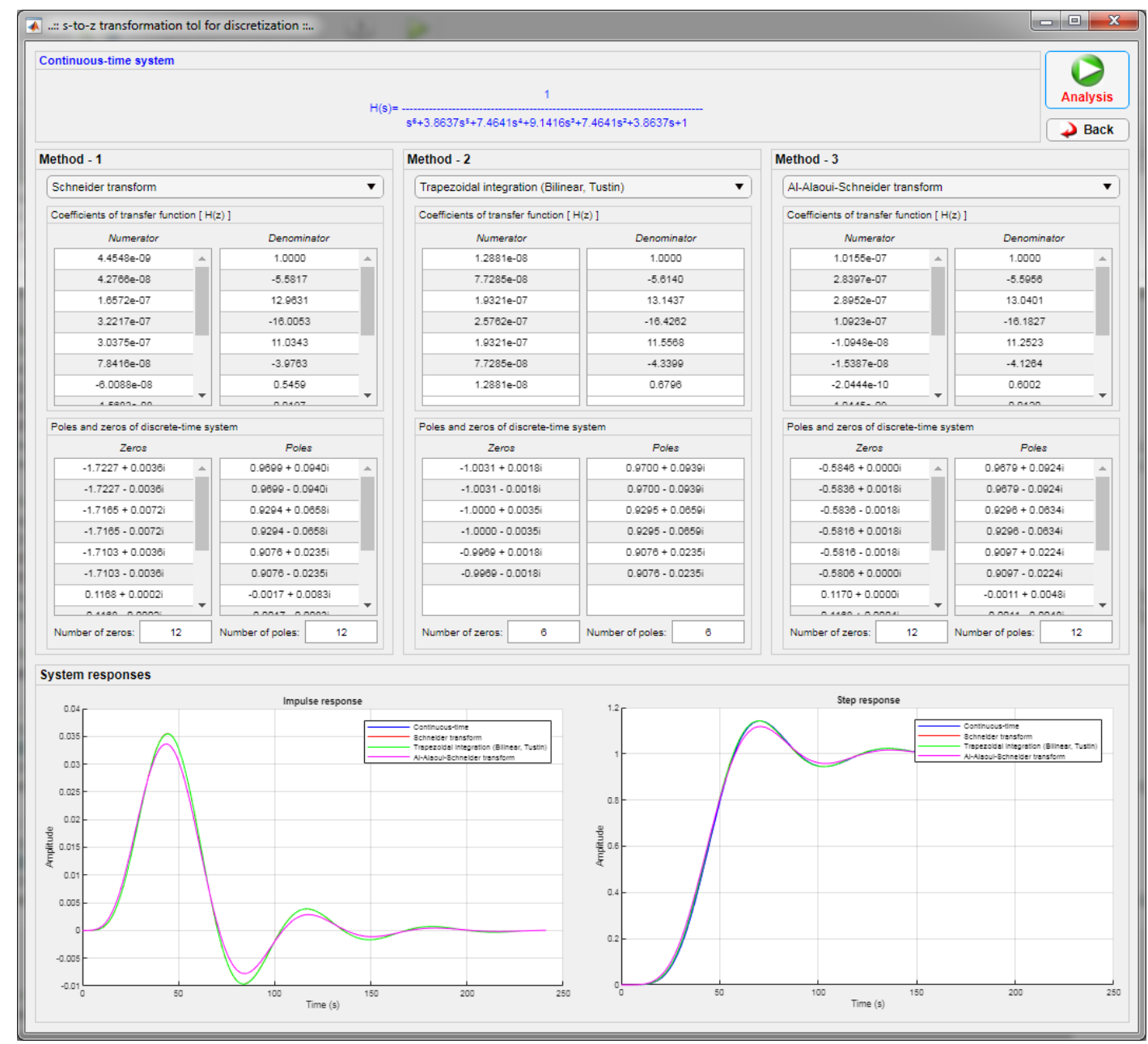

Figure 3. The screenshots for second application 


\section{CONCLUSIONS}

In this study, an application/simulator was designed out for discretization, which is one of the most important application areas of signal processing. Continuous-time systems need to be discretized in order to be used with discrete time systems (microprocessor, computer, etc.). However, discrete-time equivalents of higher order continuous-time systems are extremely difficult to obtain manually. Complex mathematical operations are performed especially for obtaining of discrete models with high accuracy (equivalence). With the software tool designed in this study - regardless of the degree of the system discretization can be done easily, quickly and effectively with many different methods. In addition, the most suitable models can be determined with comparative numerical and graphical results.

\section{REFERENCES}

[1] Katz P., (1981). Digital Control using Microprocessors. New Jersey: Prentice Hall.

[2] Franklin G.F., Powell J.D., Workman M.L., (1998). Digital Control of Dynamic Systems. 3rd ed. California: Addison-Wesley Longman.

[3] Al-Alaoui M.A., Novel stable higher order s-to-z transforms, IEEE Transactions on Circuits and Systems-I: Fundamental Theory and Applications, 48 No. 11 (2001) 1326-1329. doi: 10.1109/81.964421

[4] Al-Alaoui M.A., Linear phase low pass IIR digital differentiators, IEEE Transactions on Signal Processing, 55 No. 2 (2007) 697-706. doi: 10.1109/TSP.2006.885741

[5] Al-Alaoui M.A., Novel approach to analog-to-digital transforms, IEEE Transactions on Circuits and Systems-I: Regular Papers, 54 No. 2 (2007) 338-350. doi:10.1109/TCSI.2006.885982

[6] Ádám T., Dadvandipour S., Futás, J., Influence of discretization method on the digital control system performance, Acta Montanistica Slovaca, 8 No. 4 (2003) 197-200.

[7] Mirković D., Petković P., Litovski V., A second order s-to-z transform and its implementation to IIR filter design, COMPEL: The International Journal for Computation and Mathematics in Electrical and Electronic Engineering, 33 No. 5 (2014) 1831-1843. doi: 10.1108/COMPEL-03-2014-0058

[8] Paarmann L.D., Mapping from the s-domain to the z-domain via the magnitude-invariance method, Signal Processing, 69 No. 3 (1998) 219-228. doi: 10.1016/S0165-1684(98)00104-2

[9] Paarmann L.D., Atris Y.H., Mapping from the s-domain to the z-domain via the phase-invariance method, Signal Processing, 86 No. 2 (2006) 223-229. doi: 10.1016/j.sigpro.2005.05.007

[10] Schneider A.M., Kaneshige J.T., Groutage F.D., Higher order s-to-z mapping functions and their application in digitizing continuous-time filters, Proceedings of the IEEE, 79 No. 11 (1991) 1661-1674. doi: $10.1109 / 5.118990$

[11] James J.R., A survey of knowledge-based systems for computer-aided control system design, 1987 American Control Conference, Minneapolis (1987) 2156-2161. doi: 10.23919/ACC.1987.4789669

[12] Kessler P., Schaufelberger W., Minitools for education in control system analysis and design, IFAC Proceedings Volumes, 24 No. 4 (1991) 441-446. doi: 10.1016/S1474-6670(17)54312-8

[13] Prendergast D.P., Eydgahi A.M., 'EDCON': an educational control system analysis and design program, IEEE Transactions on Education, 36 No. 1 (1993) 42-44. doi: 10.1109/13.204814

[14] Palopoli L., Abeni L., Buttazzo G., Conticelli F., Di Natale M., Real-time control system analysis: an integrated approach, Proceedings 21st IEEE Real-Time Systems Symposium, Orlando (2000) 131-140. doi: 10.1109/REAL.2000.896003 
[15] Lincoln B., Cervin A., JITTERBUG: a tool for analysis of real-time control performance, Proceedings of the 41st IEEE Conference on Decision and Control, Las Vegas (2002) 1319-1324. doi: 10.1109/CDC.2002.1184698

[16] Ang K.H., Chong G., Li Y., PID control system analysis, design, and technology, IEEE Transactions on Control Systems Technology, 13 No. 4 (2005) 559-576. doi: 10.1109/TCST.2005.847331.

[17] Vatansever F., Hatun M., Sistem analizi eğitim simülatörü tasarımı, 2nd International Symposium on Innovative Technologies in Engineering and Science (ISITES2014), Karabuk (2014) 546-550.

[18] Hatun M., Vatansever F., Discrete time system simulator, 3rd International Symposium on Innovative Technologies in Engineering and Science (ISITES2015), Valencia (2015) 1807-1814.

[19] Vatansever F., The design of transform simulator, 5th International Symposium on Innovative Technologies in Engineering and Science (ISITES2017), Baku (2017) 289-293.

[20] Díaz J.M., Costa-Castelló R., Muñoz R., Dormido S., An interactive and comprehensive software tool to promote active learning in the loop shaping control system design, IEEE Access, 5 (2017) 1053310546. doi: 10.1109/ACCESS.2017.2712520

[21] Vatansever F., Yalcin N.A., e-Signals \& Systems: A web-based educational tool for signals and systems, Computer Applications in Engineering Education, 25 No. 4 (2017) 625-641. doi: $10.1002 /$ cae. 21826

[22] The MathWorks Inc. (2018). MATLAB , App Designer.

[23] Vatansever F., (2018). Sayısal Hesaplama ve Programlama. Ankara: Seçkin Yayıncılık.

[24] Hori N., Cormier R., Kanai K., On matched pole-zero discrete-time models, IEE Proceedings D: Control Theory and Applications, 139 No. 3 (1992) 273-278. doi: 10.1049/ip-d.1992.0036

[25] Hartley T.T., Comments on "On the nature of the Boxer-Thaler and Madwed integrators and their applications in digitizing a continuous-time system", IEEE Transactions on Automatic Control, 37 No. 5 (1992) 702-704. doi: 10.1109/9.135524

[26] Al-Alaoui M.A., Novel approach to designing digital differentiators, Electronics Letters, 28 No. 15 (1992) 1376-1378. doi: 10.1049/el:19920875

[27] Al-Alaoui M.A., Novel digital integrator and differentiator, Electronics Letters, 29 No. 4 (1993) 376378. doi: 10.1049/el:19930253

[28] Al-Alaoui M.A., Novel IIR differentiator from the Simpson integration rule, IEEE Transactions on Circuits and Systems-I: Fundamental Theory and Applications, 41 No. 2 (1994) 186-187. doi: $10.1109 / 81.269060$

[29] Al-Alaoui M.A., A class of second-order integrators and low-pass differentiators, IEEE Transactions on Circuits and Systems-I: Fundamental Theory and Applications, 42(4) (1995) 220-223. doi: $10.1109 / 81.382477$

[30] Al-Alaoui M.A., A class of numerical integration rules with first order derivatives, ACM Signum Newsletter, 31 No. 2 (1996) 25-44. doi: 10.1145/230922.230930

[31] Al-Alaoui M.A., Filling the gap between the bilinear and the backward-difference transforms: an interactive design approach, International Journal of Electrical Engineering \& Education, 34 No. 4 (1997) 331-337. doi: 10.1177/002072099703400405

[32] Al-Alaoui M.A., Al-Alaoui operator and the $\alpha$-approximation for discretization of analog systems, Facta Universitatis, Ser.: Elec. and Energ., 19 No. 1 (2006) 143-146. doi: 10.2298/FUEE0601143A 
[33] Al-Alaoui M.A., Al-Alaoui operator and the new transformation polynomials for discretization of analogue systems, Electrical Engineering, 90 No. 6 (2008) 455-467. doi: 10.1007/s00202-007-0092-0

[34] Al-Alaoui M.A., Class of digital integrators and differentiators, IET Signal Processing, 5 No. 2 (2011) 251-260. doi: 10.1049/iet-spr.2010.0107

[35] Al-Alaoui M.A., Baydoun M., Yaacoub E., Confluence of pattern recognition and signal processing: application of Al-Alaoui pattern recognition algorithm to digital filters design, IET Signal Processing, 9 No. 6 (2015) 498-505. doi: 10.1049/iet-spr.2014.0377

[36] Auger F., Some new developments on the Al-Alaoui and the Pei and Hsu s-to-z transforms, IEEE Transactions on Signal Processing, 57 No. 6 (2010) 471-475. doi: 10.1109/TCSII.2010.2048350

[37] Chen C.M., Liu F.H., The discrete-time equivalent of an analogue controller by a compensated approach, International Journal of Systems Science, 32 No. 3 (2001) 287-294. doi: $10.1080 / 002077201300029566$

[38] Chen C.M., Liu F.H., The discrete-time equivalent of an analogue controller by the parabolic approach, Proceedings of the Institution of Mechanical Engineers, Part I: Journal of Systems and Control Engineering, 215 No. 1 (2001) 29-36. doi:10.1243/0959651011539178

[39] Georgiev V., Some applied aspects of rational higher order s-z transformations, Radioengineering, 7 No. 1 (1998) 19-26.

[40] Gupta M., Jain M., Kumar B., Novel class of stable wideband recursive digital integrators and differentiators, IET Signal Processing, 4 No. 5 (2010) 560-566. doi: 10.1049/iet-spr.2009.0030

[41] Gupta M., Jain M., Kumar B., Recursive wideband digital integrator and differentiator, International Journal of Circuit Theory and Applications, 39 No. 7 (2011) 775-782. doi: 10.1002/cta.658

[42] Gupta M., Jain M., Kumar B., Wideband digital integrator and differentiator, IETE Journal of Research, 58 No. 2 (2012) 166-170. doi: 10.4103/0377-2063.96175

[43] Hamming R.W., (1989). Digital Filters. 3rd ed. New Jersey: Prentice Hall.

[44] Kowalczuk Z., Discrete approximation of continuous-time systems: a survey, IEE Proceedings-G (Circuits, Devices and Systems), 140 No. 4 (1993) 264-278. doi: 10.1049/ip-g-2.1993.0045

[45] Le Bihan J., Novel class of digital integrators and differentiators, Electronics Letters, 29 No. 11 (1993) 971-973. doi: 10.1049/el:19930647

[46] Ngo N.Q., A new approach for the design of wideband digital integrator and differentiator, IEEE Transactions on Circuits and Systems-II: Express Briefs, 53 No. 9 (2006) 936-940. doi: 10.1109/TCSII.2006.881806

[47] Papamarkos N., Chamzas C., A new approach for the design of digital integrators, IEEE Transactions on Circuits and Systems-I: Fundamental Theory and Applications, 43 No. 9 (1996) 785 791. doi: $10.1109 / 81.536749$

[48] Šekara T.B., Stojić M.R., Application of the $\alpha$-approximation for discretization of analogue systems, Facta Universitatis, Ser.: Elec. and Energ., 18 No. 3 (2005) 571-586. doi: 10.2298/FUEE0503571S

[49] Šekara T.B., New transformation polynomials for discretization of analogue systems, Electrical Engineering, 89 No. 2 (2006) 137-147. doi: 10.1007/s00202-005-0322-2

[50] Tseng C.-C., Digital integrator design using Simpson rule and fractional delay filter, IEE Proceedings of Vision, Image and Signal Processing, 153 No. 1 (2006) 79-85. doi: 10.1049/ipvis: 20045208 
[51] Upadhyay D.K., Recursive wideband digital differentiators, Electronics Letters, 46 No. 25 (2010) 1661-1662. doi: 10.1049/el.2010.2113

[52] Upadhyay D.K., Class of recursive wideband digital differentiators and integrators, Radioengineering, 21 No. 3 (2012) 904-910.

[53] Upadhyay D.K., Recursive wideband linear phase digital differentiators and integrators, 2015 International Conference on Computing Communication Control and Automation, Pune (2015) 927-931. doi: 10.1109/ICCUBEA.2015.184

[54] Upadhyay D.K., Singh R.K., Recursive wideband digital differentiator and integrator, Electronics Letters, 47 No. 11 (2011) 647-648. doi: 10.1049/el.2011.0420

[55] Wang C.-H., Lin M.-Y., Teng C.-C., On the nature of the Boxer-Thaler and Madwed integrators and their applications in digitizing a continuous-time system, IEEE Transactions on Automatic Control, 35 No. 10 (1990) 1163-1167. doi: 10.1109/9.58563 